4

\title{
A Weibull Distribution Based Technique for Downscaling of Climatic Wind Field
}

\author{
Mohamad Javad Alizadeh $^{1}$ - Mohamad Reza Kavianpour ${ }^{1}$ - Bahareh Kamranzad ${ }^{2,3}$ - Amir Etemad-Shahidi ${ }^{4,5}$ \\ Received: 30 September 2018 / Revised: 11 January 2019 / Accepted: 25 January 2019 \\ (C) Korean Meteorological Society and Springer Nature B.V. 2019
}

\begin{abstract}
This study proposes a simple approach based on Weibull distribution parameters for downscaling climatic wind speed and direction. In this method, the Weibull parameters of a Global Climate Model (GCM) are modified using Weibull parameters of the reference data (ECMWF). To correct the wind direction, the downscaling technique was applied to the eastward and northward wind components. All the wind components were simply transformed to positive values in order to fit a Weibull distribution. The unbiased wind speed was calculated by integrating the corrected wind components. Moreover, other models were considered to directly modify the wind speed (not wind components) using the same methodology. Performance and ability of the proposed approach were evaluated against the existing statistical downscaling techniques such as Multiplicative Shift Method (MSM), quantile mapping and support vector regression. In the models, the 6-h GCM wind component/speed was the sole predictor and the ECMWF reanalysis wind data was considered as the predictand. It is demonstrated that direct application of the proposed method on the wind speed slightly gives better estimation of the predictand rather than its application on wind components. The results indicate the Weibull distribution based method outperforms the other techniques for wind direction and magnitude. The method provides sound predictions for a wide range of wind speed from low to high values. By using the proposed downscaling technique for wind components, wind direction can be adjusted accordingly.
\end{abstract}

Keywords Statistical downscaling · Weibull parameters · Wind direction · Wind components · Quantile mapping

\section{Introduction}

Wind characteristics including speed and direction play an important role in the fields of coastal engineering and renewable energies. Wind field is a key element in coastal sediment

Responsible Editor: Edvin Aldrian.

Mohamad Javad Alizadeh

mjalizadeh@mail.kntu.ac.ir

1 Faculty of Civil Engineering, K.N.Toosi University of Technology, Tehran, Iran

2 Disaster Prevention Research Institute, Kyoto University, Gokasho, Uji, Kyoto 611-0011, Japan

3 Hakubi Center for Advanced Research, Kyoto University, Yoshida Honmachi, Sakyo-ku, Kyoto 606-8501, Japan

4 Griffith School of Engineering and Built Environment, Griffith University, Gold Coast 4222, Australia

5 School of Engineering, Edith Cowan University, Joondalup, WA 6027, Australia transport studies, design and construction of marine structures, wave energy extraction and wave modelling, design and installation of wind turbines, etc. It was found that quality of wind data can significantly affect outputs of numerical wave models (Liao and Kaihatu 2016; Moeini et al. 2010). Assessment of future changes in wind climate is of great interest for researchers and engineers toward sustainable development and long term benefits of any design and construction. However, global climate models (GCMs) which simulate future climate variables may need modifications due to their low spatial resolution for special applications/regional studies especially in enclosed or narrow water bodies. To that end, downscaling techniques (dynamical or statistical) are employed to convert GCM outputs from coarser to finer scales. In the dynamical approach, a numerical model is forced by boundary conditions from a GCM in a limited domain (Räisänen et al. 2004). On the other hand, in statistical approach, an empirical relationship between the predictors and predictand is employed to reproduce the GCM-simulated variable in a finer scale. Simplicity, lower computational time and less complexity have made the statistical techniques more popular than the dynamical 
downscaling approach. Multiplicative shift method (MSM), machine learning, and quantile mapping are among common types of statistical downscaling techniques which have been widely used for climate variables such as temperature and precipitation (Camici et al. 2013; Sachindra et al. 2014; Najafi et al. 2010; Sachindra et al. 2018).

Regarding wind speed downscaling, several statistical techniques have been developed for different situations (Shin et al. 2018; Tang and Bassill 2018; Winstral et al. 2017; Reyers et al. 2015; van der Kamp et al. 2012). Shirkhani et al. (2013) demonstrated that linear and nonlinear regression techniques can not estimate wind speed variation efficiently. Devis et al. (2013) applied a regression approach to downscale wind speed at the hub-height of tall wind turbines. In this study, probability density function $(p d f)$ parameters of observed local hub-height wind speed as predictand and the $p d f$ parameters of large scale atmospheric variables as predictors were correlated using an empirical relationship. Pryor and Barthelmie (2014) downscaled Weibull parameters of wind speed at 85 stations over the eastern USA. In their study, the mean and standard deviation of the relative vorticity at $500 \mathrm{hPa}$ and the mean and standard deviation of the sea-level pressure gradient were selected as predictors. Similarly, Chang et al. (2015) developed a multiple linear regression function which relates Weibull parameters of wind data in a specific location to three predictors including the mean and standard deviation of relative vorticity (obtained from GCM) as well as the mean of the sea-level pressure gradient. Shirkhani et al. (2015) used quantile mapping (QM) and nearest neighbor search to downscale wind speed at the Doha Airport station. For the QM approach, the GCM wind and observed wind speed were used as predictor and predictand, respectively. Their results indicated superiority of QM method over the other downscaling approach. Kamranzad et al. (2015) computed monthly correcting factor to modify GCM wind components. Yao et al. (2016) applied multivariate statistical technique for wind field downscaling in the Gulf of Mexico, USA. Using a linear regression between predictor and predictand, the IPCC GFDL model output with spatial resolution of 2 by 2.5 degrees were downscaled to coastal meridional and zonal wind fields with higher resolution ( 0.25 by 0.25 degrees). It is noticed that using the downscaling approach for wind components, wind direction would be modified automatically.

To sum up, it can be noticed that previous studies mainly focused on wind speed and less effort was devoted to modify wind direction in climatic data. Monahan (2012) showed that remarkable improvements in the prediction accuracy of wind components compared to wind speeds can be achieved for both daily and monthly time scales. Moreover, Porté-Agel et al. (2013) showed that a small change in wind direction can make a remarkable loss in wind farm power. In their study, 67 wind direction simulation cases from the Horns Rev. offshore wind farm were considered. Apart from wind farm power, wind direction is of great importance for a large number of practical applications in coastal engineering. However, it is not an easy task to directly perform statistical downscaling techniques on wind direction and it is usually carried out by modifying wind components (eastward and northward wind speed). Therefore, dealing with downscaling methods for wind characteristics, special attention should be given to wind direction modification.

The main objective of this study is to explore efficiency of a simple downscaling approach based on Weibull parameters of wind speed. Formerly, Weibull distribution technique has been applied for wind speed downscaling but not for wind components because it is only applicable for positive value data. In this study, the problem was resolved through a transformation and de-transformation procedure for wind components (including positive and negative values). The performance of the proposed method for downscaling of wind components and subsequently wind direction is assessed for the Persian Gulf. In this regard, GCM simulated wind speed/ components are considered as the sole predictor and the wind speed/components of ECMWF (European Center for Medium-Range Forecast) as the model predictand. Several stations in the Persian Gulf were considered for the statistical downscaling. Finally, separate models such as MSM, support vector regression (SVR) and QM with the same predictor were evaluated for comparison purposes.

\section{Study Area and Methods}

\subsection{Study Area and Data Resources}

In brief, the study area is an extension of the Indian Ocean which surrounded by Iran and countries in Arabian Peninsula. The so-called Shamal wind is recognized as the dominant wind regime in the study area especially in its northwest parts. In this study, the climatic wind data obtained from the CMIP5 (Coupled Model Intercomparison Project-Phase5) GCM model were modified based on a reference data. There are many different GCMs providing several climate variables with different temporal and spatial resolutions. In this study, 6-hly historical outputs of eastward and northward wind speed from CMCCCM model with spatial resolution of 0.75 degree (about $75 \mathrm{~km}$ in the study area) were employed as the GCM data. To downscale GCM climate variables by means of statistical techniques, a long term data records (usually observed data) are required as the reference data. However, the observed long term data is not available in the Persian Gulf. In this case, ECMWF reanalysis data is a good alternative which has been successfully used for different applications such wind and wave studies (Schindler and Jung 2018; Penalba et al. 2018; Salah et al. 2016; Han et al. 2018). The ERA-Interim data with spatial resolution of $75 \mathrm{~km}$ and temporal interval of 6-hour for a 20-year period of 19812000 were considered as reference data to develop and validate the downscaling models. It is noteworthy that for a reliable 
154 model development and an efficient downscaling, enough data 155 should be available. This can be challenging due to lack of 156 enough measurement or required data. Moreover, the data 157 record length also depends to the purpose of the study and 158 type of the climatic variable. The main purpose of this 159 study was to evaluate efficiency of Weibull distribution 160 based technique for wind speed/component downscaling 161 and to compare its performance against the existing 162 methods. Generally, considering 20 year time slices for 163 downscaling and climate change studies is reasonable and 164 in line with the previous studies (Wandres et al. 2017; 165 Hemer et al. 2013). However, it is recommended to employ 166 longer period for practical applications in future. Different 167 stations in the Persian Gulf have been selected for down168 scaling purposes (Fig. 1). These points were chosen in a 169 way to reflect spatial variation of the wind and also dom170 inant wind directions. Moreover, they have been considered 171 with different distance from shoreline to evaluate GCM 172 wind consistency with those of ECMWF from nearshore 173 to offshore.

\subsection{Downscaling Methods}

\subsubsection{Weibull Distribution Technique}

175

This method aims to downscale Weibull distribution parameters of GCM instead of directly modifying wind record. The distribution can be appropriately used for observed histogram of wind data for a wide range of circumstances (He et al. 2010; Shin et al. 2018). In some studies, Weibull distribution parameters have been used to downscaling wind speed by finding a regression relationship between Weibull parameters of wind speed and some other climatic variables such as mean of sea level pressure, mean and standard deviation of relative vorticity (Curry et al. 2012; Chang et al. 2015). Two main parameters of this distribution i.e. scale $(A)$ and shape $(k)$ describe the characteristics of Weibull distribution. The scale parameter and shape parameter are related to the mean and peakedness of the distribution, respectively. For $k=1$ and $k=2$, the exponential and Rayleigh distributions are obtained, respectively. The probability density function $(p d f)$ of Weibull distribution
176

177

178

179

180

181

182

183

184

185

186

187

188

189

190

191

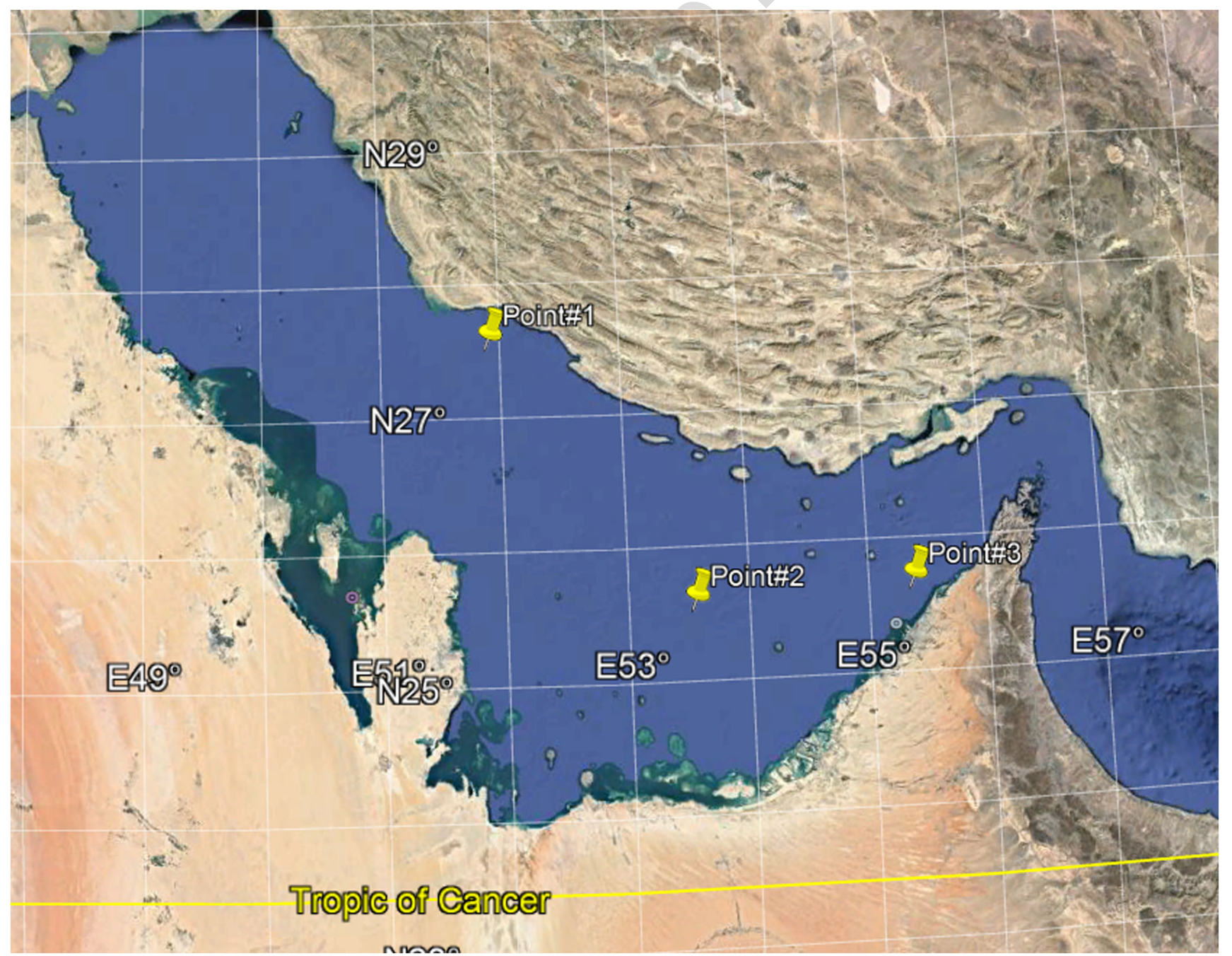

Fig. 1 Study area and selected points 
for positive values of wind speed $(W \geq 0)$ can be mathematically expressed as:

$f(W)=\frac{k}{A}\left(\frac{W}{A}\right)^{k-1} \exp \left[-\left(\frac{W}{A}\right)^{k}\right]$

where $A$ and $k$ can be obtained through the maximum likelihood estimation as the following iterative equations (Chang et al. 2003):

$k=\left(\frac{\sum_{i=1}^{n} W_{i}^{k} \ln \left(W_{i}\right)}{\sum_{i=1}^{n} W_{i}^{k}}-\frac{\sum_{i=1}^{n} \ln \left(W_{i}\right)}{n}\right)^{-1}$

$A=\left(\frac{1}{n} \sum_{i=1}^{n} W_{i}^{k}\right)^{1 / k}$

where $n$ is the number of samples.

In this study, this method is employed to modify the Wiebull parameters of $A$ and $k$ for GCM simulated data based on the ECMWF wind data. In this regard, the datasets of ECMWF and GCM are divided into two subsets of calibration and validation. The Weibull distribution parameters for calibration period of ECMWF $\left(A_{E C M W F}^{c a l}, k_{E C M W F}^{c a l}\right)$ and GCM $\left(A_{G C M}^{c a l}, k_{G C M}^{c a l}\right)$ are obtained first. Afterwards the difference between Weibull parameters in calibration period $\left(D_{A(i)}\right.$, $\left.D_{k(i)}\right)$ is considered as the correction factor to be applied to Weibull parameters in the validation period $\left(A_{G C M}^{v a l}, k_{G C M}^{v a l}\right)$ as:

$A_{G C M(i)}^{\prime v a l}=A_{G C M(i)}^{v a l}+D_{A(i)}$

$k_{G C M(i)}^{\prime \text { val }}=k_{G C M(i)}^{v a l}+D_{k(i)}$

where $A^{\prime}$ and $k^{\prime}$ are the modified scale and shape parameters of the validation period.

\subsubsection{Multiplicative Shift Method (MSM)}

For wind speed modification, the MSM serves as a correcting factor for the predictor. This approach focuses on the mean value of the predictands. This method has been employed for downscaling of daily GCM rainfall (Ines and Hansen 2006), wind speed (Breslow and Sailor 2002) and wind components (Kamranzad et al. 2016). In this study, the latter one has been used in which the correcting factor for wind speed and components were computed for each month. These factors for wind speed and components are computed as follows:

$\beta_{w_{i}}=\frac{\bar{W}_{E C M W F(i)}}{\bar{W}_{G C M . C M C C(i)}} \beta_{u_{i}}=\frac{\left|\bar{u}_{E C M W F(i)}\right|}{\left|u_{G C M . C M C C(i)}\right|} \beta_{v_{i}}=\frac{\left|\bar{v}_{E C M W F(i)}\right|}{\left|\bar{v}_{G C M . C M C C(i)}\right|} i=1,2, . .12$

where $\beta_{w_{i}}, \beta_{u_{i}}, \beta_{v_{i}}$ are correcting factors for wind speed, eastward and northward wind speed, respectively. The bar over $W$, $u, v$ represents the average values and $i$ from 1 to 12 denote the month. The numerators and denominators in eq. 1 stand for predictands and predictors, respectively. As wind components can contain both negative and positive values, the absolute value was used when averaging the daily wind components.

\subsubsection{Support Vector Regression (SVR)}

Support vector regression (SVR) as a machine learning technique uses linear or nonlinear kernels to fit a relationship between predictor and predictand during training period. The nonlinear kernel functions transform data into a higher dimensional feature space for linear separation. Given a training dataset of $\left\{\left(x_{i}, y_{i}\right)\right\}_{i=1}^{n}$ where $n$ is the sample size and $x$ and $y$ represent input and output data, the method is applied to map the input space into an $n$-dimensional feature space using a nonlinear function $(\varphi(x))$. Basically, the SVR function can be expressed as (Liu et al. 2014):

$f(x)=(w \cdot \varphi(x))+b$

where $w$ denotes the weight vector $w=\left\{w_{1}, \ldots, w_{n}\right\}$, and $b$ represents the bias. Unlike traditional regressions which use least square error criterion, the coefficients including the weight vector and the bias are estimated by defining a new loss function known as the $\varepsilon$-insensitive loss function in SVR (Liu et al. 2014):

$L_{\varepsilon}(f(x), y)=\left\{\begin{array}{lr}|f(x)-y|-\varepsilon & \text { for }|f(x)-y| \geq \varepsilon \\ 0 & \text { Otherwise }\end{array}\right.$

where $L_{\varepsilon}$ is the loss function, $\mathrm{y}$ is the target value, and $\varepsilon$ is the region of $\varepsilon$ insensitivity (defined by user).

In SVR, the weight vector is derived using the regularized risk function as follows:

$R_{\text {reg }}=C \frac{1}{n} \sum_{i=1}^{n} L_{\varepsilon}\left(f\left(x_{i}\right), y_{i}\right)+\frac{1}{2}\|w\|^{2}$

where $\frac{1}{2}\|w\|^{2}$ and $C$ are called regularization term and a user defined constant, respectively. Equation (9) can be rewritten as a optimization problem with the following cost function and constraints (Vapnik 2013):

minimize $\frac{1}{2}\|w\|^{2}+C \sum_{i=1}^{n}\left(\xi_{i}, \xi_{i}^{*}\right)$

subject to $\left\{\begin{array}{c}y_{i}-\left(w \cdot \varphi\left(x_{i}\right)+b\right) \leq \varepsilon+\xi_{i} \\ \left(w \cdot \varphi\left(x_{i}\right)+b\right)-y_{i} \leq \varepsilon+\xi_{i}^{*} \\ \xi_{i} \geq 0, \xi_{i}^{*} \geq 0, i=1, \ldots, n\end{array}\right.$

where $\xi_{i}$ and $\xi_{i}^{*}$ are the positive slack variables to measure the training samples' deviation outside the $\varepsilon$-insensitivity zone. The SVR regression function can be formulated in general form as (Vapnik 2013):

$f(x)=\sum_{i=1}^{n}\left(a_{i}-a_{i}^{*}\right) K\left(x, x_{i}\right)+b$

where $a_{i}, a_{i}^{*} \geq 0$ are the Lagrangian multipliers that satisfy theequality $a_{i} a_{i}^{*}=0$; and $K\left(x, x_{i}\right)$ is the kernel function (Liu 
et al. 2014). Further details of SVM and SVR can be found in Vapnik (2013).

\subsubsection{Quantile Mapping}

This method aims to correct entire distribution of the climatic variable by mapping the empirical cumulative distribution function $(c d f)$ of variables on the observed $c d f$. Quantile mapping has been widely employed to downscale different climatic variables such as temperature, precipitation and wind speed $(\mathrm{Li}$ et al. 2010; Sachindra et al. 2014; Themeß1 et al. 2012; Fereidoon and Koch 2018; Tang and Bassill 2018). In the QM approach, the dataset is divided into two parts of calibration and validation in which the latter part is used to evaluate performance of the method. Afterwards, the method is applied to downscaling future GCM simulated data with the same correction algorithm for the present and future time series. Based on the purpose and data characteristics, different versions of QM techniques can be applied. Generally, they follow the same frameworks with slightly difference in correction algorithm. In this study, two versions of QM denoting with $\mathrm{QM}^{+}$and $\mathrm{QM}^{*}$ are taken under consideration. In brief, main steps toward QM downscaling method are as follows:

1- Developing empirical cumulative functions for reference data and GCM simulated variable.

2- Estimating the correction factor for calibration period based on the QM version. In case of using $\mathrm{QM}^{+}$, the correction factor $\left(R^{+}\right)$is estimated as the difference between $c d f$ of observed and GCM data (Eq. 8). For QM*, the correction factor $\left(R^{*}\right)$ is calculated as the ratio between $c d f$ of observed data and GCM simulated data (Eq. 9).

$$
\begin{aligned}
\mathrm{R}_{i}^{+}\left[c d f_{X_{G C M_{i}^{f u t}}}\left(X_{G C M_{i}^{\text {fut }}}\right)\right] & =c d f_{X_{R e f_{i}^{h i s}}^{-1}}\left[c d f_{X_{G C M_{i}^{\text {fut }}}}\left(X_{G C M_{i}^{\text {fut }}}\right)\right] \\
& -c d f_{X_{G C M_{i}^{h i s}}^{-1}}\left[c d f_{X_{G C M}^{\text {fut }}}\left(X_{G C M_{i}^{\text {fut }}}\right)\right]
\end{aligned}
$$

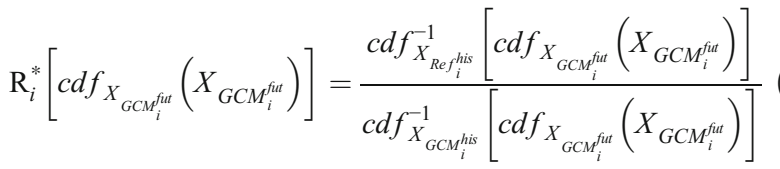

Here $c d f_{X_{G C M}^{\text {fit }}}$ and $X_{G C M_{i}^{\text {fut }}}$ are empirical cumulative distribution function and value of the climatic variable for future scenario, respectively. $c d f_{X_{R e} f_{i}^{h i s}}^{-1}$ and $c d f_{X_{G C M_{i}^{h i s}}}^{-1}$ are inverse empirical cumulative $c d f$ for historical period of observed and GCM simulated data.

3- Applying the estimated factors to modify the future GCM data by adding $R_{i}^{+}$or multiplying $R_{i}^{*}$ in future GCM data depending on the QM version. This step can be expressed as eqs. 10 and 11 for $\mathrm{QM}^{+}$and $\mathrm{QM}^{*}$ :

$$
\begin{aligned}
& X_{G C M_{i, Q M^{+}}^{f u t}}=X_{G C M_{i}^{f u t}}+\mathrm{R}_{i}^{+} \\
& X_{G C M_{i, Q M^{*}}^{\text {fut }}}=X_{G C M_{i}^{\text {fut }}}{ }^{*} \mathrm{R}_{i}^{*}
\end{aligned}
$$

where $X_{G C M_{i, Q M^{+}}^{\text {fut }}}$ and $X_{G C M_{i, Q M^{*}}^{f u t}}$ are the modified GCM simulated wind data for month $i$ when $\mathrm{QM}^{+}$and $\mathrm{QM}^{*}$ are employed.

\subsection{Modelling Procedure and Performance Evaluation}

The main contribution of this study is to adopt a robust Weibull distribution based technique to modify both wind speed and wind direction whereas it has been already applied only for wind speed downscaling. Generally, the Weibull distribution is only applicable for positive data records while the wind components can include both positive and negative values. This study overcomes this issue by proposing an appropriate data transformation and de-transformation process. To assess performance of different downscaling techniques for wind speed/components, the 6-hourly CMCC-CM GCM northward near surface wind speed (v) and eastward near surface wind speed $(u)$ was used as predictor. The same components of ECMWF 6-hourly data were used as predictand. Both ECMWF and GCM wind datasets were divided into calibration (1981-1990) and validation (1991-2000) subsets. For the model development, two strategies have been employed.In the first strategy, the models were directly applied on wind speed $\left(W=\sqrt{u^{2}+v^{2}}\right)$ while in the second one, the downscaling techniques were used for the wind components $(u, v)$. It should be noted that by modifying the wind components, the wind direction would be modified automatically. Generally, main steps of the modelling procedure toward downscaling wind speed and components can be summarized as: 1- data preparation 2- selection of predictors and predictands, 3- applying the models to the data in calibration period and obtaining correcting factors/algorithms, 4- modifying wind speed and components in validation period, 5- performance evaluation of different models.

The 6-hourly data of wind components $(u, v)$ for 3 different stations in the Persian Gulf were obtained from GCM outputs and ECMWF reanalysis data. These points represent different characteristics in terms of distance from nearshore (offshore or onshore) and the dominant wind direction. For downscaling purpose, the GCM data are usually assessed and modified based on reference/observed data. However, due to lack of long term wind record in different points of the study area, 
ERA-Interim reanalysis data were used as reference data or predictand. As discussed before, four different statistical techniques (MSM, SVR, QM, and Weibull) were applied for downscaling of wind speed components. In MSM, the correcting factor for each variable in each month was computed as the ratio of monthly average of ECMWF 6-hourly data and the corresponding values of GCM output. The coefficients obtained in calibration period were then applied to modify wind speed and components during validation period. Dealing with SVR, a support vector regression model was fitted on the calibration dataset. Afterwards, it was used to predict wind characteristics for validation data. The procedure is the same for wind speed and its components. Using QM approach for wind speed, the correction was made by multiplying GCM wind speed in validation period in the ratio of 6-hourly ECMWF and 6hourly GCM wind speed of calibration data. For the wind components, $c d f$ of the GCM $u$ and $v$ outputs in validation were corrected for each month by adding the monthly $c d f$ difference between ECMWF and GCM. The main reason to apply multiplicative coefficient $\left(R_{i}^{*}\right.$ ) for wind speed was to avoid having negative values for wind speed. On the other hand, for the wind components, applying the multiplicative method leads to extremely high values (in cases the GCM wind components are close to zero). Therefore, the additive coefficient $\left(R_{i}^{+}\right)$is expected to represent a better estimation. The proposed Weibull based technique used the difference between the distribution parameters of wind speed/ components in the calibration data to correct the distribution parameters of the GCM wind speed/components in the validation period. However, it should be noticed that the Weibull distribution is only applicable for positive $(X \geq 0)$ data while the wind components include both negative and positive values. Therefore, to overcome this problem, the whole data related to wind components $(u, v)$ were simply transformed to positive values. After mapping the data based on modified Weibull parameters, the wind component data were transformed back to their original ranges. Finally, the wind speed and direction were computed using modified wind components. Fig. 2 depicts key steps of the study.

To assess the performance of downscaling techniques for wind speed, different statistical parameters including average, skew, quartiles and extreme values (Ave, Skew, $W_{25}, W_{50}, W_{75}, W_{95}$ and, $W_{99}$ ) were used to measure the models' performance. For each parameter and based on its deviation from the reference value, relative difference in percent is computed and method with minimum relative error is recognized as the best method. To evaluate efficiency of each downscaling method for wind direction, wind roses were also compared with those of the reference data.

\section{Results and Discussion}

\subsection{Wind Speed}

\subsubsection{Modification of Wind Speed}

In the first strategy, the wind speed $(W)$ was directly corrected in which the correcting factors were computed using different methods for wind speed. In this regard, wind speed computed from GCM simulated wind data were used as the sole predictor and the wind speed obtained from ECMWF wind data were used as predictand. Obtained statistical parameters of different methods and their average relative error during validation period are presented in Table 1 .

Considering the minimum error criteria, the proposed Weibull based method is superior to the other downscaling techniques. For all the three stations in the Persian Gulf, the method provides the closest average and skewness to those of the reference data. Wind speed average is of great importance for renewable energy studies. By comparing average values of ECMWF and GCM wind speeds, it can be understood that GCM simulated data underestimate wind speed for the studied stations. Therefore, the proposed method can be served as a suitable approach to improve accuracy of the wind speed under future scenarios. Regarding the quartiles, the estimated wind speed from Weibull based technique is in a good agreement with those of the ECMWF data. Furthermore, the method showed excellent capability in the estimation of extreme values (e.g. $W_{95}, W_{99}$ ) which is essential in design of marine structure, wave climate studies and risk assessment. Apart from the proposed method, the MSM and $\mathrm{QM}^{*}$ techniques have fair performances in the downscaling of wind speed using only the GCM wind speed. On the other hand, the SVR model does not provide a reliable estimation of wind speed.

To provide more insight, boxplots and probability density functions of the reference wind speed and downscaled wind speed during the validation period are illustrated in Fig. 3.

As observed from Fig. 3a, there is a good agreement between quartiles of the results obtained from Weibull downscaling technique with those of the ECMWF wind speed in all of the stations. Considering outlier data located outside the whiskers (red points in Fig. 3a), it can be concluded that the Weibull method has the best performance compared with the other downscaling techniques. Regarding the $p d f$ plot (Fig. 3b), the ECMWF wind speed and the GCM data (downscaled with Weibull technique) have a very similar distribution and there is a good match between these two datasets. The GCM output tends to underestimate the wind speed compared with the corresponding values of ECMWF. The MSM and $\mathrm{QM}^{*}$ improve the GCM wind speed distribution toward ECMWF but still underestimate wind speed. Moreover, they have a deficiency in estimation of extreme values. Due to
425

426

427

428

429

430

431

432

433

434

435

436

437

438

439

440

441

442

443

444

445

446

447

448

449

450

451

452

453

454

455

456

457

458

459

460

461

462

463

464

465

466

467

468

469

470

471 


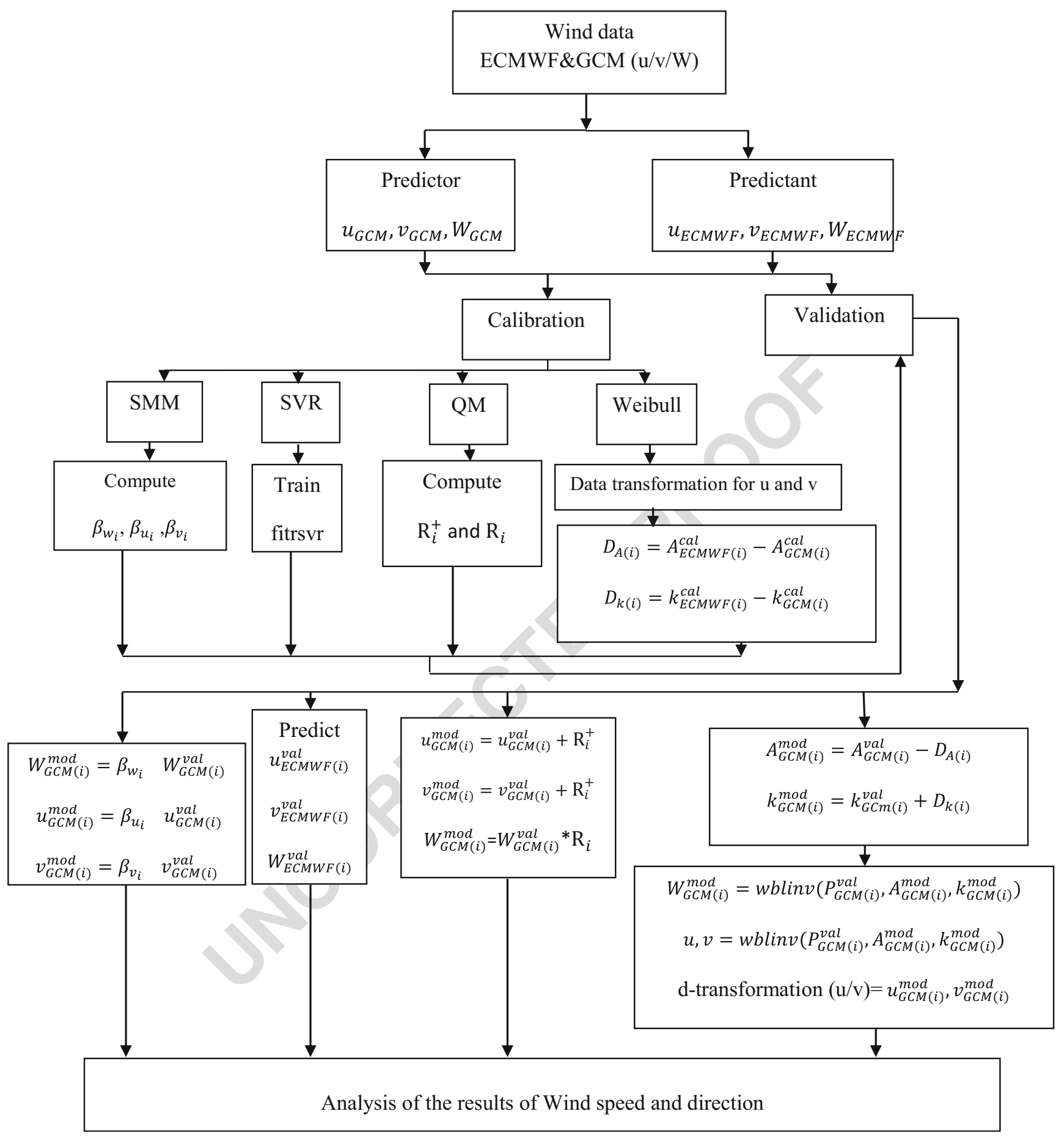

Fig. 2 Flowchart of the study

importance of extreme values of wind data for risk assessment and practical applications, the Weibull based method can be efficiently employed to estimate high values.

\subsubsection{Modification of Wind Components}

An alternative approach is to employ the techniques for wind components and finally calculate the resulting wind speed based on modified components. Furthermore, by downscaling of the wind components, wind direction is modified automatically. This is of great importance because the usual statistical downscaling techniques cannot be employed for wind direction modification, directly. Therefore, the methods were applied to downscale wind components, individually. The results obtained from the different models for different stations during validation period are presented in Table 2. 
Q4 t1.1 Table 1 Wind speed statistics obtained from wind speed downscaling (validation period)

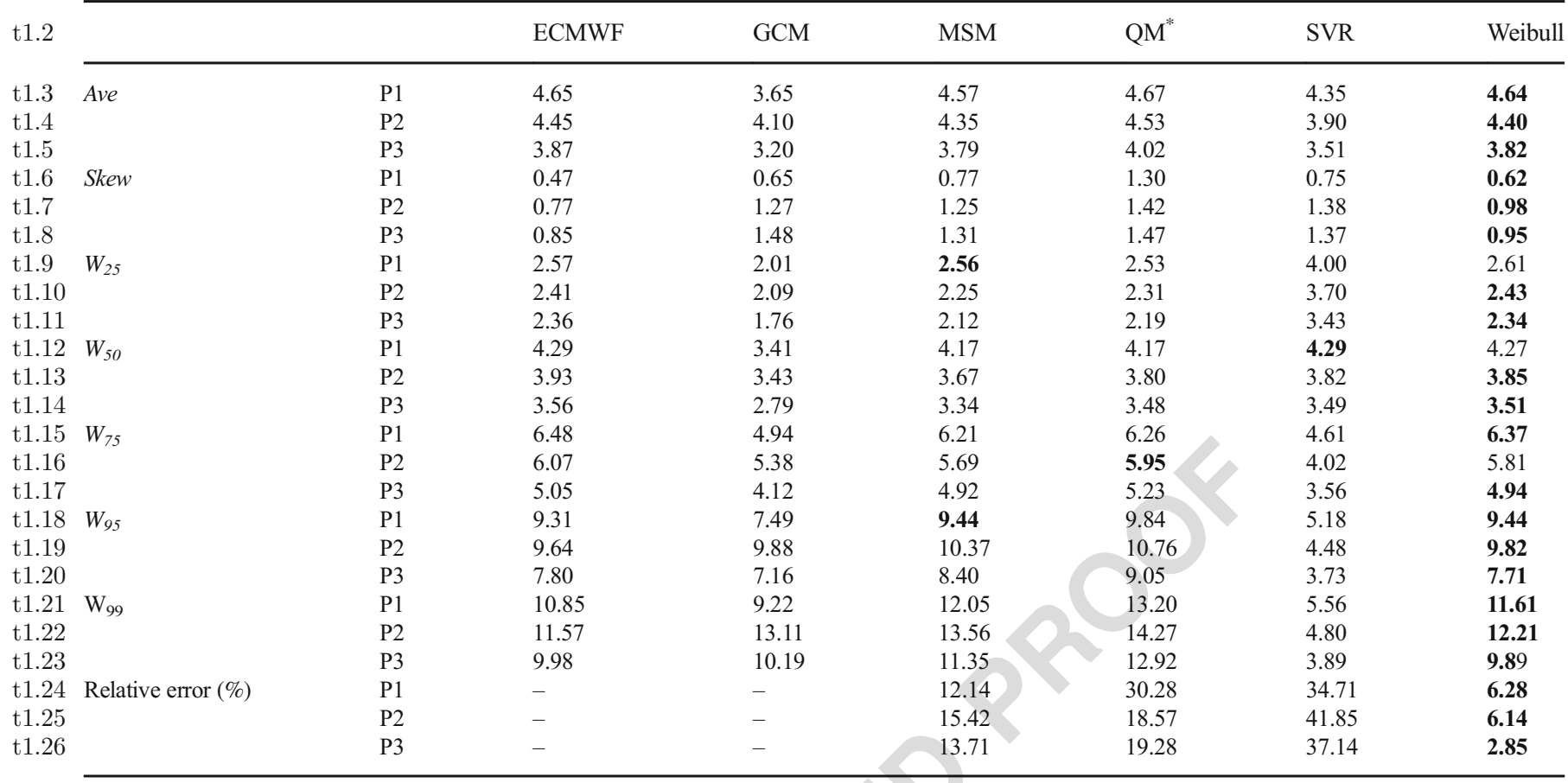

486 According to Table 2, the Weibull based downscaling tech487 nique shows the best performance among the applied tech488 niques (the lowest error). However, the outputs of MSM and 489 QM models are comparable to those of the reference data 490 (ECMWF) for some cases. The SVR model with the used 491 input structure lacks enough accuracy for wind component 492 downscaling. However, the Weibull method still remains as 493 the best one for extreme value predictions. The quartiles of wind speed are estimated appropriately when the proposed technique is employed. Moreover, it outperforms the others in terms of average and skewness of wind speed. Therefore, it is expected that the wind speed obtained using the Weibull based method has the closest distribution with that of the reference data of wind speed. Fig. 4 illustrates boxplots and probability density functions of the different models.

The boxplots (Fig. 4a) indicate superiority of the Weibull based method over the other techniques. It can be found that the extreme values computed from downscaled wind components with the proposed method has the highest correlation with the corresponding values of the ECMWF (reference) wind speed. Similarly, the wind speed distribution for Weibull based method has the best fit with the distribution of the reference wind speed. Fig. $4 \mathrm{~b}$ shows that although the $\mathrm{MSM}$ and $\mathrm{QM}^{+}$models improve wind speed distribution compared with that of GCM, they still has some remarkable deviations from the wind speed distribution. In Fig. $4 \mathrm{~b}$ for ECMWF, the downward limbs corresponding to Weibull based model is truncated in $14-16 \mathrm{~m} / \mathrm{s}$ while for MSM and $\mathrm{QM}^{+}$models the limbs extends up to $20 \mathrm{~m} / \mathrm{s}$ and further. Thus, considering all the evaluating criteria, the proposed downscaling technique outperforms the other methods with the same input variables.

Figures 3 and 4 show a roughly similar pattern in estimation of wind speed even though a slightly better fit can be observed in Fig. 3 where Weibull approach is employed. However, for QM method, the outliers in wind speed represent better consistencies with the reference data when the downscaling method is applied on the wind components rather than its application directly to the wind speed. Regardless the Weibull method, Tables 1 and 2 demonstrate that there is no preference for input parameter (either wind components or wind speed). Considering the results of Weibull downscaling technique, it can be concluded that it has a slightly better performance when it is directly applied to wind speed rather than wind components. This may be initiated from data transformation in case of wind components while for direct implication to wind speed there is no need to transform the data. However, van der Kamp et al. (2012) stated that wind components are usually estimated with better skill than wind speed.

\subsection{Wind Direction}

Direct downscaling of wind direction is not an easy task, especially for wave coming from north sector where the direction could be 0 or 360 . Thus, downscaling wind components has the advantage of modifying wind direction without ambiguity. Wind directions were obtained for ECMWF, raw GCM data, downscaled wind components of MSM, $\mathrm{QM}^{+}$, SVR, and Weibull based models. The results are illustrated as rose plots in Figs. 5, 6 and 7. It should be noticed that no new models 
a)
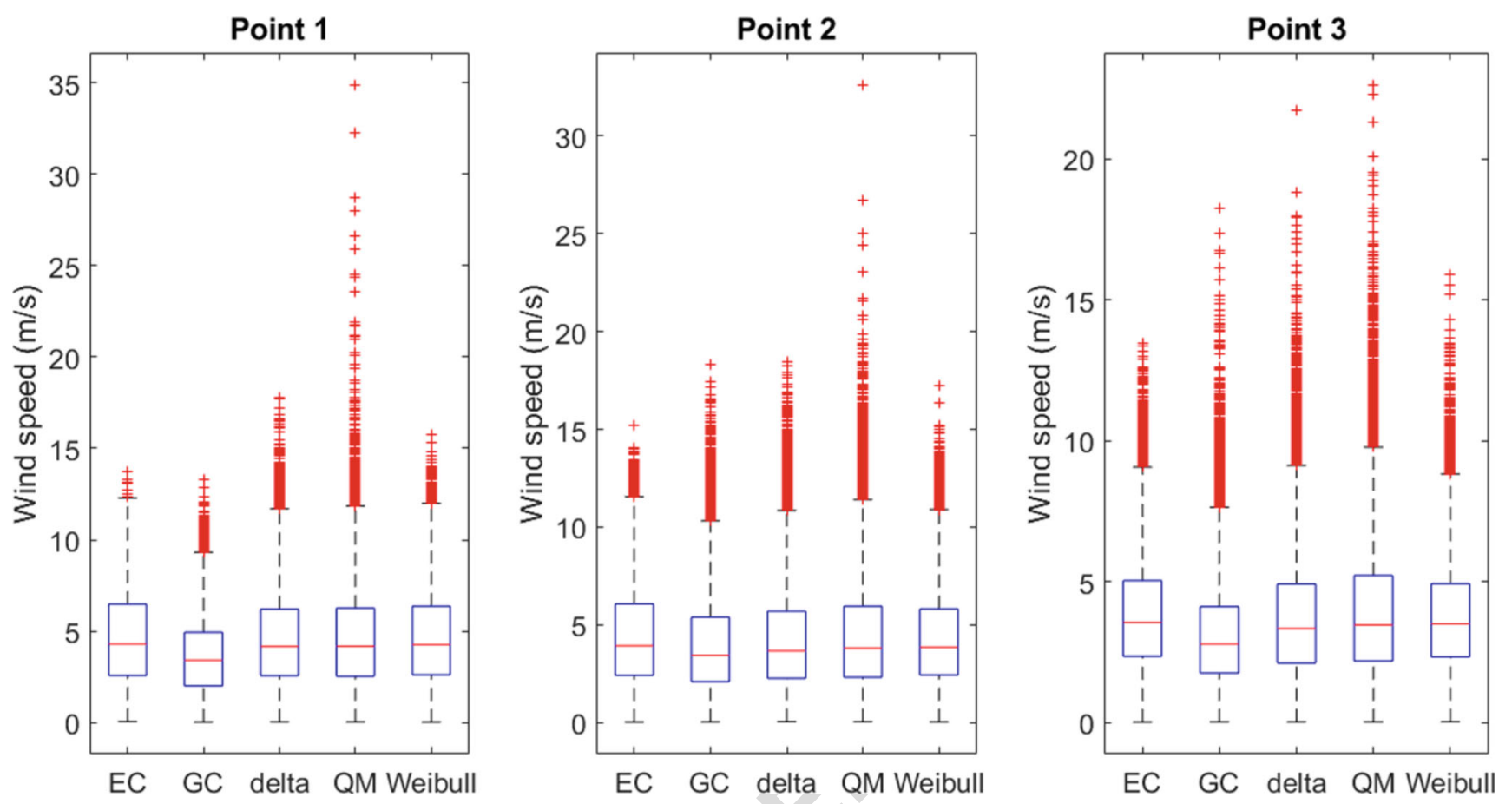

b)
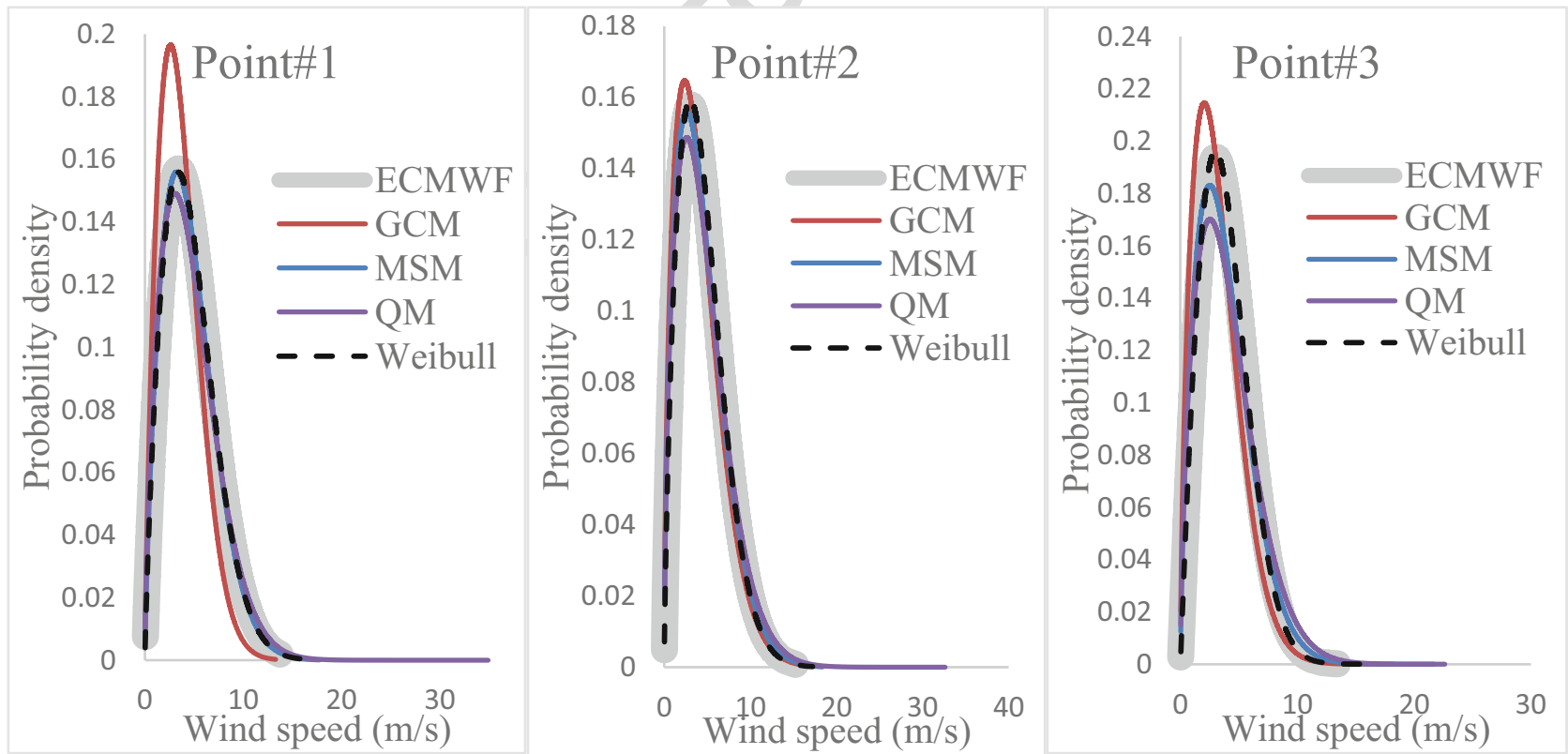

Fig. 3 a boxplots $\mathbf{b} p d f \mathrm{~s}$ of reference and downscaled wind speed

were run for wind direction modification, but only the output of downscaling models for wind components were used to obtain modified wind direction.

Generally speaking, these figures imply that GCM simulated wind data only predict the dominant wind direction (the direction with highest frequency) accurately. However, at station 1 which is located in a nearshore location, there are some inconsistencies between ECMWF and GCM wind direction (due to topographical influences). The GCM with spatial resolution of $75 \mathrm{~km}$ may need to be regionalized with reference data to reflect the wind field of the nearshore areas accordingly. In other words, models with coarse spatial
550 
t2.1 Table 2 Wind speed analysis obtained from wind component downscaling in validation period

\begin{tabular}{|c|c|c|c|c|c|c|c|c|}
\hline $\mathrm{t} 2.2$ & & & ECMWF & GCM & MSM & $\mathrm{QM}^{+}$ & SVR & Weibull \\
\hline $\mathrm{t} 2.3$ & Ave & $\mathrm{P} 1$ & 4.65 & 3.65 & 4.78 & 4.47 & 3.24 & 4.57 \\
\hline $\mathrm{t} 2.4$ & & $\mathrm{P} 2$ & 4.45 & 4.10 & 4.48 & 4.45 & 7.48 & 4.31 \\
\hline $\mathrm{t} 2.5$ & & P3 & 3.87 & 3.20 & 3.81 & 3.57 & 2.10 & 3.66 \\
\hline $\mathrm{t} 2.6$ & Skew & $\mathrm{P} 1$ & 0.47 & 0.65 & 0.70 & 0.67 & 0.74 & 0.50 \\
\hline $\mathrm{t} 2.7$ & & $\mathrm{P} 2$ & 0.77 & 1.27 & 1.23 & 1.27 & 1.32 & 1.05 \\
\hline $\mathrm{t} 2.9$ & $W_{25}$ & P1 & 2.57 & 2.01 & 2.71 & 2.52 & 2.58 & 2.60 \\
\hline $\mathrm{t} 2.10$ & & $\mathrm{P} 2$ & 2.41 & 2.09 & 2.31 & 2.27 & 5.51 & 2.32 \\
\hline $\mathrm{t} 2.11$ & & P3 & 2.36 & 1.76 & 2.03 & 1.86 & 1.50 & 1.99 \\
\hline $\mathrm{t} 2.12$ & $W_{50}$ & $\mathrm{P} 1$ & 4.29 & 3.41 & 4.39 & 4.05 & 3.03 & 4.24 \\
\hline $\mathrm{t} 2.13$ & & P2 & 3.93 & 3.43 & 3.77 & 3.72 & 6.83 & 3.74 \\
\hline $\mathrm{t} 2.18$ & $W_{95}$ & P1 & 9.31 & 7.49 & 9.78 & 9.12 & 5.03 & 9.08 \\
\hline $\mathrm{t} 2.19$ & & $\mathrm{P} 2$ & 9.64 & 9.88 & 10.67 & 10.90 & 13.66 & 9.87 \\
\hline $\mathrm{t} 2.20$ & & P3 & 7.80 & 7.16 & 8.67 & 8.30 & 3.48 & 7.90 \\
\hline $\mathrm{t} 2.21$ & $W_{99}$ & P1 & 10.85 & 9.22 & 12.14 & 11.13 & 5.55 & 10.75 \\
\hline $\mathrm{t} 2.22$ & & $\mathrm{P} 2$ & 11.57 & 13.11 & 13.81 & 13.86 & 16.98 & 12.32 \\
\hline $\mathrm{t} 2.23$ & & P3 & 9.98 & 10.19 & 11.72 & 11.60 & 4.22 & 10.20 \\
\hline $\mathrm{t} 2.24$ & Relative error $(\%)$ & $\mathrm{P} 1$ & - & - & 11 & 9.14 & 36.14 & 2.43 \\
\hline $\mathrm{t} 2.25$ & & $\mathrm{P} 2$ & - & - & 15.57 & 16.28 & 67.42 & 9.14 \\
\hline $\mathrm{t} 2.26$ & & P3 & - & - & 15.85 & 19.29 & 46.57 & 7.00 \\
\hline
\end{tabular}

556 resolution are unable to resolve detailed topography of a par557 ticular region (Sailor et al. 2000; Staffell and Pfenninger 558 2016). As observed from Fig. 1, stations 1 and 2 are nearer 559 to the land than station 3 which is located farther (offshore). 560 Consequently stations 1 and 2 are more influenced by land 561 mask effect. Thus, GCM wind direction in stations 1 and 2 are 562 expected to have more deviations from ECMWF wind direction. 563 Following Figs. 5, 6 and 7, it can be concluded that the best 564 agreement between wind direction of ECMWF and GCM is 565 obtained at station 3 which has the longest distance from the 566 land. Moreover, the wind direction of GCM and ECMWF in 567 station 2 shows a better consistency than station 1 that may reflect 568 its longer distance from shoreline. The MSM does not change the 569 GCM wind direction, remarkably. Due to obtaining absolute 570 values for multiplicative coefficient, this method only increases 571 the frequency of wind direction based on magnitude of the coef572 ficient. The SVR method with the used input structure is not suitable for wind speed and direction modifications. Apart from insufficient input variable to train the SVR model accordingly, presence of outliers may cause misleading results or inaccurate predictions of wind speed/components. In regression models such as SVR, outliers may have moderate to severe impacts on predictand (Soukissian and Karathanasi 2016). A more sophisticated model including some other relevant variables or suitable dealing with outlier impacts may improve the accuracy. The $\mathrm{QM}^{+}$and Weibull based methods provide roughly similar estimation of wind direction. However, the Weibull based method is superior to $\mathrm{QM}^{+}$for directional frequency of extreme or high values of the wind speed (shown in green and blue). The GCM wind direction at station 2 (located in offshore) fairly follows the same pattern of ECMWF wind direction. However, for nearshore locations which are more important in terms of coastal engineering applications, wind direction should be modified because topographical influences are neglected in GCM which run in global scale with a coarse grid. Concerning ECMWF wind direction at station 1, about $32 \%$ of the winds have direction in range of 315-345 degrees which are in close correlation with wind direction of the Weibull model (about $28 \%$ with the same direction). A similar pattern with quantitative analysis for frequency of wind direction at other stations (not shown for the sake of brevity) implies superiority of the Weibull based model for matching the GCM wind direction to reference data.

\subsection{Comparison of the Applied Methods and Discussion}

Considering results of the different methods for wind speed and wind component downscaling, the Weibull based model
598 599 
a)
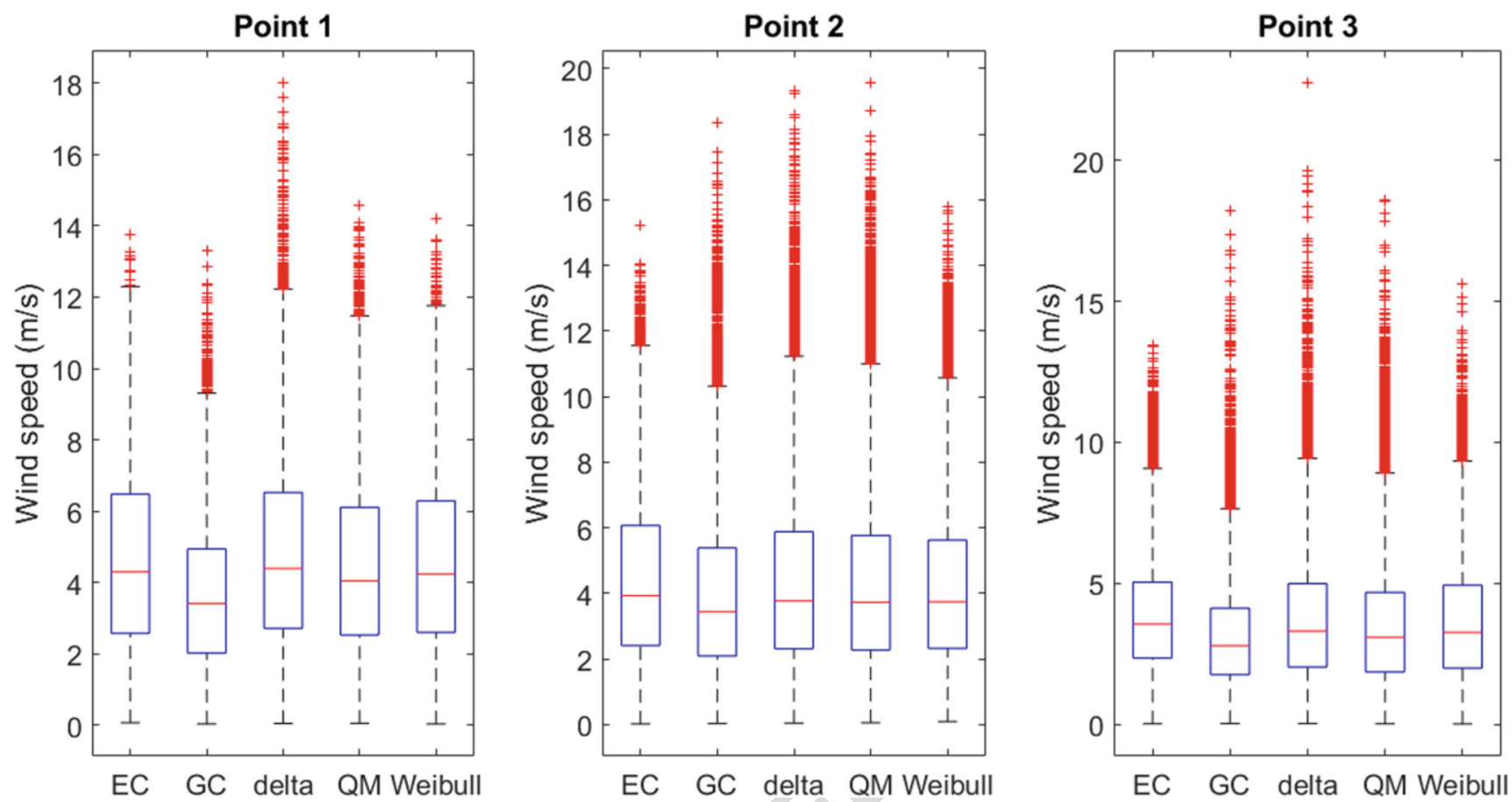

b)
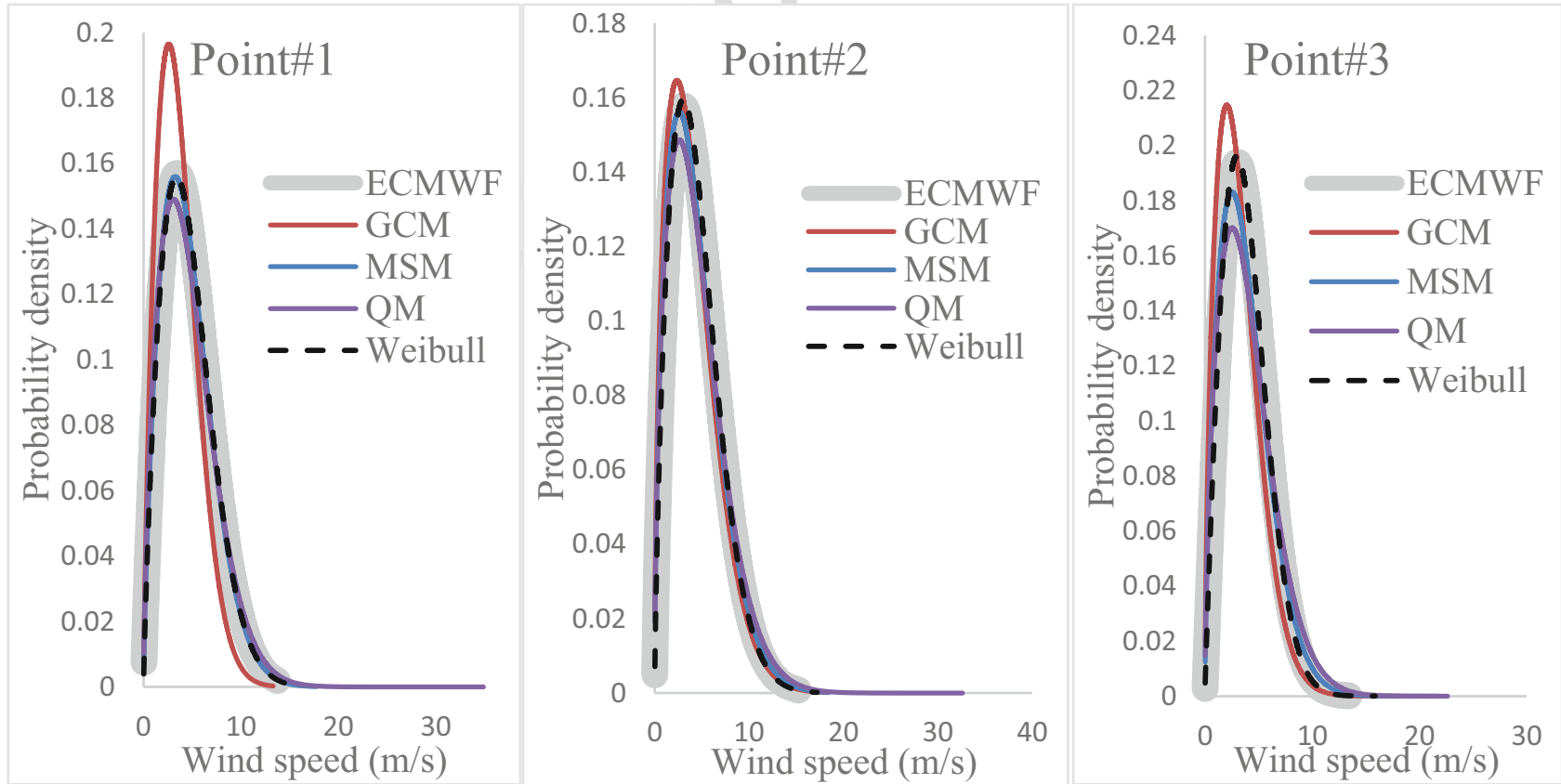

Fig. 4 a boxplots $\mathbf{b} p d f$ s of wind speed computed from downscaled wind components

was recognized as the best model. For direct wind speed downscaling, it gives the closest average, skewness and quartiles for all the considered stations. Both for wind speed and its components, the lowest errors are obtained using Weibull based method, MSM, and quantile mapping approach, respectively. The proposed downscaling method showed excellent performance in estimation of the extreme values of wind speed for the three stations. For example, it predicts the extreme value $\left(W_{99}\right)$ of $10.85,11.57$, and $9.98 \mathrm{~m} / \mathrm{s}$ for points 1 to 3 as $11.61,12.21$, and $9.89 \mathrm{~m} / \mathrm{s}$, respectively.
607 608 609 610 611 

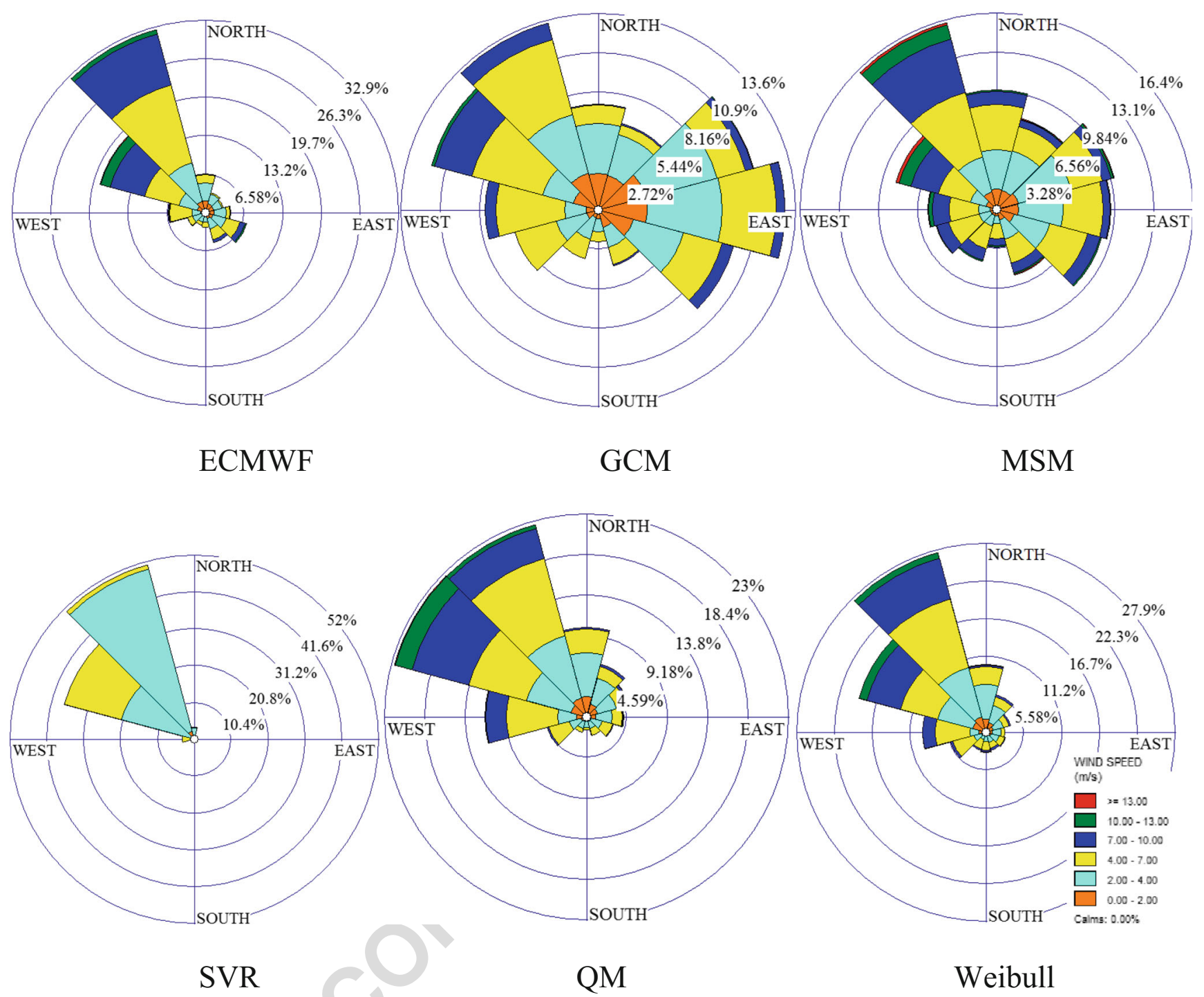

Fig. 5 Rose plot for different downscaling models, station 1

Regardless the Weibull distribution based method, the results of the other downscaling techniques considering two different sets of input variables (i.e. GCM computed wind speed in the first approach, and wind components as second approach) do not differ significantly. In other words, estimates of wind speed considering both approaches are close to each other. However, for Weibull based method the former slightly outperforms the latter. This can be because of data transformation for wind components and avoiding negative values in Weibull distribution. Moreover, the QM technique for wind components provides better estimates of extreme values than the QM technique directly applied to wind speed. The QM approach has been employed with different formulations using two approaches (multiplicative and additive for first and second approach respectively) to avoid negative values in wind speed estimation and to avoid extremely high values in wind components as well. Dealing with QM approach, the temporal sequence of the wind time series is disrupted because it involves distribution mapping even though the statistical moments and some statistical attributes of the CDF will get corrected. However, the MSM and Weibull distribution based methods do not suffer from this limitation and the temporal sequence of the downscaled time series in these models will remain the same as the original time series. The wind speed probability distribution function for the proposed model and ECMWF data roughly overlap each other when the method is directly applied for wind speed downscaling. However, applying the proposed Weibull downscaling method for wind components slightly underestimates the wind speed $p d f$ whereas it has the advantage of modifying wind direction without any extra effort. The main assumption embedded within the application of Weibull based model is that the wind data follow Weibull distribution which is in accordance with the previous studies (He et al. 2010; Monahan 2012).

The outliers in wind data may represent extreme values which are of great importance in extreme event studies. 

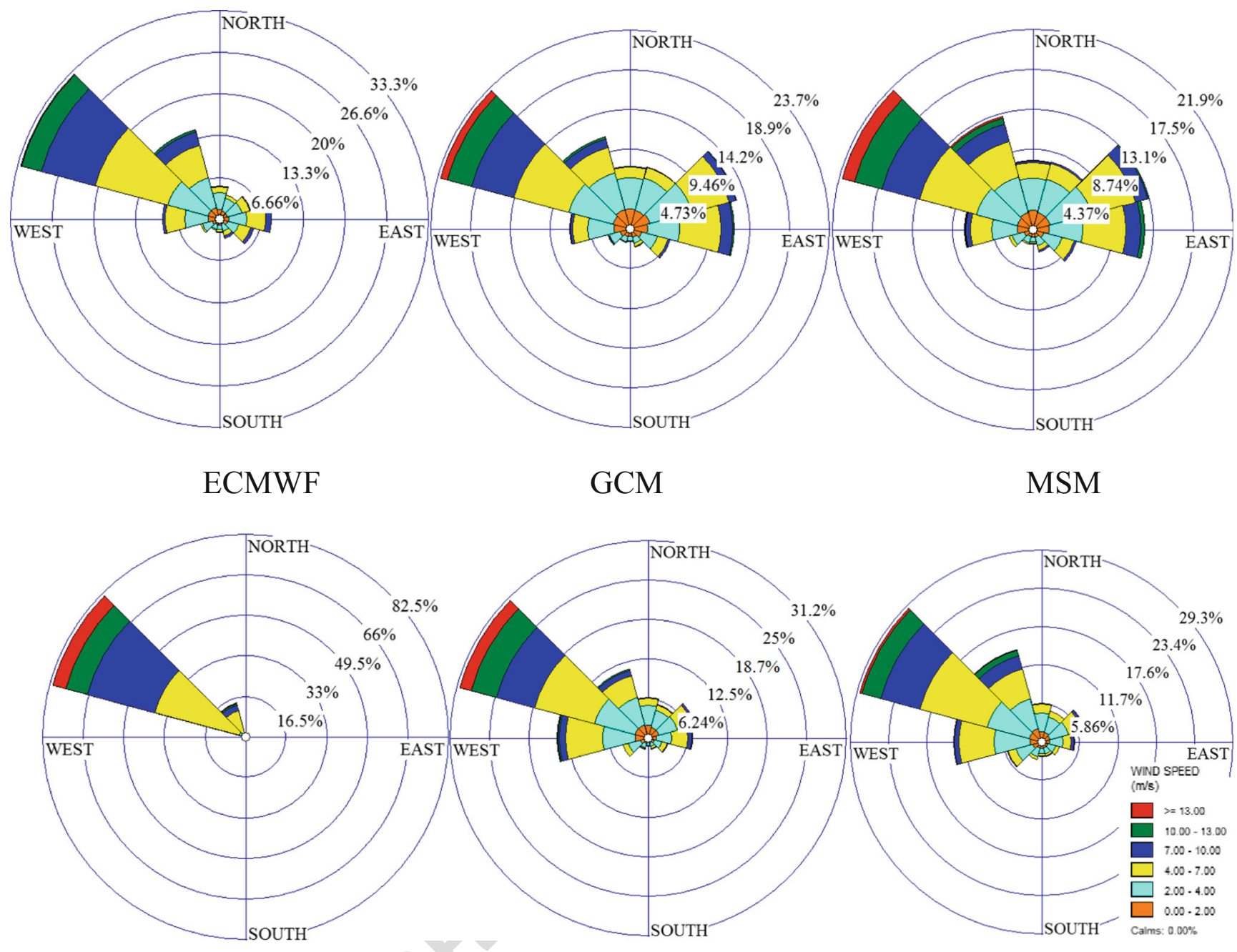

SVR

QM

Weibull

Fig. 6 Rose plot for different downscaling models, station 2

Through the downscaling procedure, outlier/extreme value data were not excluded in the predictive models. Therefore, the outliers were remained and expected to appear in the predictions. In the MSM and QM models, extremely high values of wind speed or wind components are multiplied or added to a constant number which lead to extreme values as the models' outputs. Moreover, in the Weibull distribution based method, the outliers/extremes were included as the model input and consequently they are expected to appear as the model outputs as well.

The rose plots of wind direction obtained from the different downscaling models for wind components show that the proposed Weibull method has the best performance in terms of magnitude and direction. It was found that the application of the proposed model can significantly improve wind direction accuracy, especially for nearshore stations where the topographical influences are not resolved in GCM simulation. Moreover, it has a good capability to map wind direction of
GCM toward ECMWF wind direction for offshore (station no. 2) and near the Strait (station no. 3). The quantile mapping approach showed good efficiency for wind direction modifications albeit it has some deficiencies in estimation of frequency and magnitude of extreme values of wind speed. On the other hand, the MSM technique does not change the wind direction significantly because it deals with absolute values of wind components (disregards negative values in wind components). The SVR model fails to modify GCM wind direction appropriately due to its deficiency in wind component estimation.

\section{Summary and Conclusions}

Wind speed and direction are important variables for many practical applications in coastal and ocean engineering, environmental and atmospheric sciences, and renewable energy 


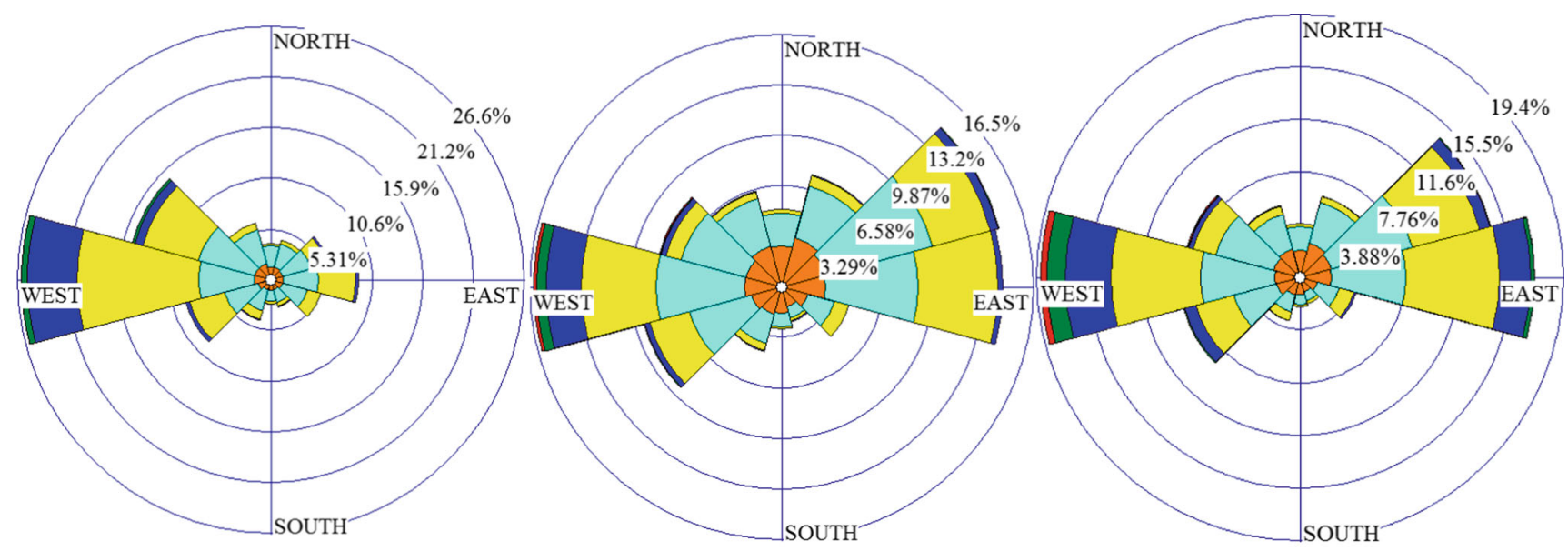

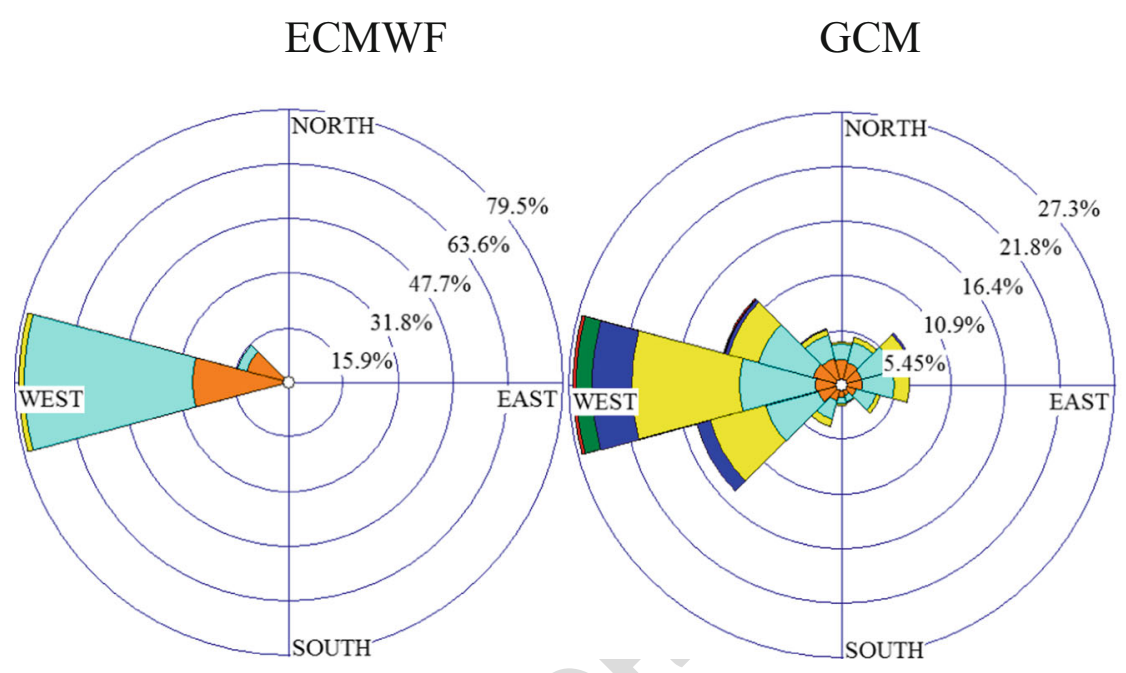

SVR
QM

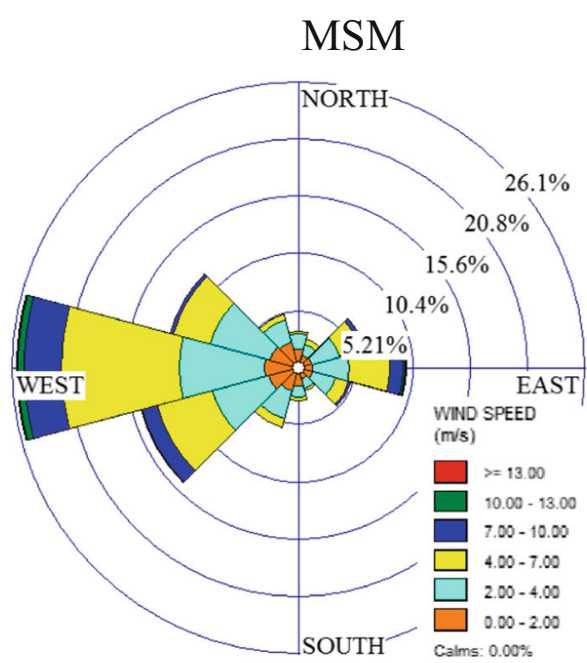

Weibull

Fig. 7 Rose plot for different downscaling models, station 3

industries. Global circulation models (GCMs) running on coarse scale can not consider fine topographical influences in which they play an important role in regional studies of wind climate. This study explored the efficiency and ability of a simple statistical downscaling approach based on Weibull distribution parameters for wind speed and wind components. The GCM simulation of near surface eastward and northward wind speeds were modified based on ERA-Interim reanalysis data of ECMWF. Different data mining methods such as SVR, MSM and quantile mapping with the same input variable as the Weibull based technique were tuned during calibration period and used to modify the wind speed and its components during validation period. The method modified Weibull shape and scale parameters of the GCM simulated wind components and wind speed based on their difference with those of the reference data (means 6-hourly ECMWF near surface wind data). The main advantage of the proposed method compared with the previous ones based on Weibull distribution parameters is that the method only uses the GCM simulated wind data as the sole predictor. The proposed method for wind speed downscaling has less complexity in terms of computational time and required information compared with those of previous studies which included characteristics of sea level pressure and relative vorticity as well.

Results demonstrated the efficiency of the proposed model for both wind speed and wind component downscaling. The Weibull based method yielded a good estimation of wind speed/components for validation period in terms of average, skewness, quartiles and extreme values. The $p d f$ of the proposed method for wind speed and components has the best match with those of the reference wind data. It outperformed the other statistical downscaling techniques such as MSM, SVR and QM. It was found that SVR with the current input variable does not provide reliable estimation of wind speed/ 
components. Generally speaking, performance of the MSM and QM approach were assessed satisfactory for a wide range of data variation even though they had some deficiencies in estimation of extreme values. Between two strategies applied for wind speed downscaling, it was found that the downscaling models give slightly a better distribution of wind speed when they are directly used to downscale wind speed instead of being employed for wind components. On the other hand, application of the downscaling techniques for wind components may lead to automatic correction of wind direction.

This study also examined ability of different approaches to modify GCM wind direction and the methods were employed for wind component downscaling. It was found that the proposed Weibull based method outperforms the others in terms of accuracy. Afterwards, the QM has a good performance roughly similar with the proposed model except slight shortcoming in estimation of frequency and magnitude of extreme values. The MSM does not significantly change the original GCM wind direction because of using absolute value to compute multiplicative coefficient. However, it has the potential to change the wind frequency based on the magnitude of the correction coefficients. Generally, MSM, QM and Weibull based models represent the dominant wind direction properly while the proposed method is superior over the others in terms of accuracy of direction and magnitude.

The method introduced in this study can be successfully applied to modify and downscaling wind speed and direction for a wide range of applications from onshore to offshore stations. Moreover, its capability to catch high values of wind speed may serve as a proxy in extreme value analysis for risk assessment and preventing natural hazards in coastal area. Due to importance of downscaling techniques in climate change studies, employing the proposed method for climatic wind data under future scenarios are of great interest for purposes of renewable energy, wind and wave power assessments, meteorology, etc. The method has less complexity in terms of computational time and cost while its performance is higher or comparable with the exiting statistical downscaling techniques.

Publisher's Note Springer Nature remains neutral with regard to jurisdictional claims in published maps and institutional affiliations.

\section{References}

Breslow, P.B., Sailor, D.J.: Vulnerability of wind power resources to climate change in the continental United States. Renew. Energy. 27(4), 585-598 (2002)

Camici, S., Brocca, L., Melone, F., Moramarco, T.: Impact of climate change on flood frequency using different climate models and downscaling approaches. J. Hydrol. Eng. 19(8), 04014002 (2013)

Chang, T.-J., Wu, Y.-T., Hsu, H.-Y., Chu, C.-R., Liao, C.-M.: Assessment of wind characteristics and wind turbine characteristics in Taiwan. Renew. Energy. 28(6), 851-871 (2003)
Chang, T.-J., Chen, C.-L., Tu, Y.-L., Yeh, H.-T., Wu, Y.-T.: Evaluation of the climate change impact on wind resources in Taiwan Strait. Energy Convers. Manag. 95, 435-445 (2015)

Curry, C.L., van der Kamp, D., Monahan, A.H.: Statistical downscaling of historical monthly mean winds over a coastal region of complex terrain. I. Predicting wind speed. Clim. Dyn. 38(7-8), 1281-1299 (2012)

Devis, A., van Lipzig, N.P., Demuzere, M.: A new statistical approach to downscale wind speed distributions at a site in northern Europe. J. Geophys. Res.-Atmos. 118(5), 2272-2283 (2013)

Fereidoon, M., Koch, M.: SWAT-MODSIM-PSO optimization of multicrop planning in the Karkheh River basin, Iran, under the impacts of climate change. Sci. Total Environ. 630, 502-516 (2018)

Han, K., Choi, J., Kim, C.: Comparison of statistical post-processing methods for probabilistic wind speed forecasting. Asia-Pac. J. Atmos. Sci. 54(1), 91-101 (2018)

He, Y., Monahan, A.H., Jones, C.G., Dai, A., Biner, S., Caya, D., Winger, K.: Probability distributions of land surface wind speeds over North America. J. Geophys. Res. Atmos. 115(D4), (2010)

Hemer, M., McInnes, K., Ranasinghe, R.: Projections of climate changedriven variations in the offshore wave climate off south eastern Australia. Int. J. Climatol. 33(7), 1615-1632 (2013)

Ines, A.V., Hansen, J.W.: Bias correction of daily GCM rainfall for crop simulation studies. Agric. For. Meteorol. 138(1-4), 44-53 (2006)

Kamranzad, B., Etemad-Shahidi, A., Chegini, V., Yeganeh-Bakhtiary, A.: Climate change impact on wave energy in the Persian Gulf. Ocean Dyn. 65(6), 777-794 (2015)

Kamranzad, B., Chegini, V., Etemad-Shahidi, A.: Temporal-spatial variation of wave energy and nearshore hotspots in the Gulf of Oman based on locally generated wind waves. Renew. Energy. 94, 341352 (2016)

Li, H., Sheffield, J., Wood, E.F.: Bias correction of monthly precipitation and temperature fields from intergovernmental panel on climate change AR4 models using equidistant quantile matching. J. Geophys. Res. Atmos. 115(D10) (2010)

Liao, Y.-P., Kaihatu, J.M.: The effect of wind variability and domain size in the Persian Gulf on predicting nearshore wave energy near Doha, Qatar. Appl. Ocean Res. 55, 18-36 (2016)

Liu, Z., Zhou, P., Chen, G., Guo, L.: Evaluating a coupled discrete wavelet transform and support vector regression for daily and monthly streamflow forecasting. J. Hydrol. 519, 2822-2831 (2014)

Moeini, M., Etemad-Shahidi, A., Chegini, V.: Wave modeling and extreme value analysis off the northern coast of the Persian Gulf. Appl. Ocean Res. 32(2), 209-218 (2010)

Monahan, A.H.: Can we see the wind? Statistical downscaling of historical sea surface winds in the subarctic Northeast Pacific. J. Clim. 25(5), 1511-1528 (2012)

Najafi, M.R., Moradkhani, H., Wherry, S.A.: Statistical downscaling of precipitation using machine learning with optimal predictor selection. J. Hydrol. Eng. 16(8), 650-664 (2010)

Penalba, M., Ulazia, A., Ibarra-Berastegui, G., Ringwood, J., Sáenz, J.: Wave energy resource variation off the west coast of Ireland and its impact on realistic wave energy converters' power absorption. Appl. Energy. 224, 205-219 (2018)

Porté-Agel, F., Wu, Y.-T., Chen, C.-H.: A numerical study of the effects of wind direction on turbine wakes and power losses in a large wind farm. Energies. 6(10), 5297-5313 (2013)

Pryor, S., Barthelmie, R.: Hybrid downscaling of wind climates over the eastern USA. Environ. Res. Lett. 9(2), 024013 (2014)

Räisänen, J., Hansson, U., Ullerstig, A., Döscher, R., Graham, L., Jones, C., Meier, H., Samuelsson, P., Willén, U.: European climate in the late twenty-first century: regional simulations with two driving global models and two forcing scenarios. Clim. Dyn. 22(1), 13-31 (2004)

Reyers, M., Pinto, J.G., Moemken, J.: Statistical-dynamical downscaling for wind energy potentials: evaluation and applications to decadal 
Soukissian, T.H., Karathanasi, F.E.: On the use of robust regression methods in wind speed assessment. Renew. Energy. 99, 12871298 (2016)

Staffell, I., Pfenninger, S.: Using bias-corrected reanalysis to simulate current and future wind power output. Energy. 114, 1224-1239 (2016)

Tang, B.H., Bassill, N.P.: Point downscaling of surface wind speed for forecast applications. J. Appl. Meteorol. Climatol. 57(3), 659-674 (2018)

Themeß1, M.J., Gobiet, A., Heinrich, G.: Empirical-statistical downscaling and error correction of regional climate models and its impact on the climate change signal. Clim. Chang. 112(2), 449-468 (2012)

van der Kamp, D., Curry, C.L., Monahan, A.H.: Statistical downscaling of historical monthly mean winds over a coastal region of complex terrain. II. Predicting wind components. Clim. Dyn. 38(7-8), 1301$1311(2012)$

Vapnik, V.: The nature of statistical learning theory. Springer science \& business media, (2013)

Wandres, M., Pattiaratchi, C., Hemer, M.A.: Projected changes of the southwest Australian wave climate under two atmospheric greenhouse gas concentration pathways. Ocean Model. 117, 70-87 (2017)

Winstral, A., Jonas, T., Helbig, N.: Statistical downscaling of gridded wind speed data using local topography. J. Hydrometeorol. 18(2), 335-348 (2017)

Yao, Z., Xue, Z., He, R., Bao, X., Song, J.: Statistical downscaling of IPCC Sea surface wind and wind energy predictions for US east coastal ocean, Gulf of Mexico and Caribbean Sea. J. Ocean Univ. China. 15(4), 577-582 (2016)
859 of significant wave height in a coastal area under RCPs climate change scenarios. Natural Hazards Review. 17(1), 04015016 (2015) 


\section{AUTHOR QUERIES}

\section{AUTHOR PLEASE ANSWER ALL QUERIES.}

Q1. City has been provided in affiliation 5, please check if it is correct.

Q2. Please check if all equations are captured and presented correctly.

Q3. Figure 2,5-7 contains text below the minimum required font size of $6 \mathrm{pts}$ inside the artwork, and there is no sufficient space available for the text to be enlarged. Please provide replacement figure file.

Q4. Please specify the significance of the bold entries reflected inside Tables 1 and 2 by providing a description in the form of a table footnote.

Q5. Please supply/verify the standard abbreviation of the journal name in Reference Shirkhani, $\mathrm{H}$ et al 2015. 


\section{AUTHOR'S PROOF!}

\section{Metadata of the article that will be visualized in OnlineFirst}

Article Title

A Weibull Distribution Based Technique for Downscaling of Climatic Wind Field

Article Sub-Title

Article Copyright Year

Korean Meteorological Society and Springer Nature B.V. 2019

(This will be the copyright line in the final PDF)

Journal Name

Asia-Pacific Journal of Atmospheric Sciences

\begin{tabular}{|c|c|c|}
\hline \multirow{7}{*}{ Corresponding Author } & Family Name & Alizadeh \\
\hline & Given Name & Mohamad Javad \\
\hline & Suffix & \\
\hline & Division & Faculty of Civil Engineering \\
\hline & Organization & K.N.Toosi University of Technology \\
\hline & Address & Tehran, Iran \\
\hline & e-mail & mjalizadeh@mail.kntu.ac.ir \\
\hline \multirow{7}{*}{ Author } & Family Name & Kavianpour \\
\hline & Particle & \\
\hline & Given Name & Mohamad Reza \\
\hline & Suffix & \\
\hline & Division & Faculty of Civil Engineering \\
\hline & Organization & K.N.Toosi University of Technology \\
\hline & Address & Tehran, Iran \\
\hline \multirow{9}{*}{ Author } & $\begin{array}{l}\text { Family Name } \\
\text { Particle }\end{array}$ & Kamranzad \\
\hline & Given Name & Bahareh \\
\hline & Suttix & ח. \\
\hline & Division & Disaster Prevention Research Institute \\
\hline & Organization & Kyoto University \\
\hline & Address & Gokasho, Uji, Kyoto 611-0011, Japan \\
\hline & Division & Hakubi Center for Advanced Research \\
\hline & Organization & Kyoto University \\
\hline & Address & $\begin{array}{l}\text { Yoshida Honmachi, Sakyo-ku, Kyoto 606-8501, } \\
\text { Japan }\end{array}$ \\
\hline \multirow{5}{*}{ Author } & $\begin{array}{l}\text { Family Name } \\
\text { Particle }\end{array}$ & Etemad-Shahidi \\
\hline & Given Name & Amir \\
\hline & Suffix & \\
\hline & Division & $\begin{array}{l}\text { Griffith School of Engineering and Built } \\
\text { Environment }\end{array}$ \\
\hline & Organization & Griffith University \\
\hline
\end{tabular}




\section{AUTHOR'S PROOF!}

\begin{tabular}{|c|c|c|}
\hline & $\begin{array}{l}\text { Address } \\
\text { Division } \\
\text { Organization } \\
\text { Address }\end{array}$ & $\begin{array}{l}\text { Gold Coast 4222, Australia } \\
\text { School of Engineering } \\
\text { Edith Cowan University } \\
\text { Joondalup, WA 6027, Australia }\end{array}$ \\
\hline & Received & 30 September 2018 \\
\hline Schedule & $\begin{array}{l}\text { Revised } \\
\text { Accepted }\end{array}$ & $\begin{array}{l}11 \text { January } 2019 \\
25 \text { January } 2019 \\
\end{array}$ \\
\hline Abstract & \multicolumn{2}{|c|}{$\begin{array}{l}\text { This study proposes a simple approach based on Weibull distribution } \\
\text { parameters for downscaling climatic wind speed and direction. In this } \\
\text { method, the Weibull parameters of a Global Climate Model (GCM) } \\
\text { are modified using Weibull parameters of the reference data } \\
\text { (ECMWF). To correct the wind direction, the downscaling technique } \\
\text { was applied to the eastward and northward wind components. All the } \\
\text { wind components were simply transformed to positive values in } \\
\text { order to fit a Weibull distribution. The unbiased wind speed was } \\
\text { calculated by integrating the corrected wind components. Moreover, } \\
\text { other models were considered to directly modify the wind speed (not } \\
\text { wind components) using the same methodology. Performance and } \\
\text { ability of the proposed approach were evaluated against the existing } \\
\text { statistical downscaling techniques such as Multiplicative Shift } \\
\text { Method (MSM), quantile mapping and support vector regression. In } \\
\text { the models, the 6-h GCM wind component/speed was the sole } \\
\text { predictor and the ECMWF reanalysis wind data was considered as } \\
\text { the predictand. It is demonstrated that direct application of the } \\
\text { proposed method on the wind speed slightly gives better estimation } \\
\text { of the predictand rather than its application on wind components. } \\
\text { The results indicate the Weibull distribution based method } \\
\text { outperforms the other techniques for wind direction and magnitude. } \\
\text { The method provides sound predictions for a wide range of wind } \\
\text { speed from low to high values. By using the proposed downscaling } \\
\text { technique for wind components, wind direction can be adjusted } \\
\text { accordingly. }\end{array}$} \\
\hline $\begin{array}{l}\text { Keywords (separated by } \\
\text { '-') }\end{array}$ & \multicolumn{2}{|c|}{$\begin{array}{l}\text { Statistical downscaling - Weibull parameters - Wind direction - Wind } \\
\text { components - Quantile mapping }\end{array}$} \\
\hline Foot note information & \multicolumn{2}{|c|}{ Responsible Editor: Edvin Aldrian. } \\
\hline
\end{tabular}

